\title{
CORD SERUM FERRITIN AS BIOCHEMICAL MARKER IN IRON DEFICIENCY ANEMIA
}

Sherin Stephen ${ }^{1}$, Jyothy Kuriakose ${ }^{2}$

\section{HOW TO CITE THIS ARTICLE:}

Sherin Stephen, Jyothy Kuriakose. "Cord Serum Ferritin as Biochemical Marker in Iron Deficiency Anemia". Journal of Evolution of Medical and Dental Sciences 2014; Vol. 3, Issue 30, July 28; Page: 8490-8494, DOI: $10.14260 /$ jemds/2014/3075

ABSTRACT: Iron deficiency anemia is by far the most frequent type of anemia seen in pregnancy, accounting for $90 \%$ or more of all cases. Iron deficiency anemia has adverse consequences on infant development. Therefore maternal anemia should be prevented and treated. Serum ferritin is the single best non-invasive test and is a very useful and reliable index of iron stores especially during pregnancy, with low levels indicating iron deficiency. While infants born to anemic mother are themselves not anemic, they do not suffer from low iron stores. The main aim of the study is to establish cord serum ferritin as a biochemical marker in iron deficiency anemia. The specific objectives of this study is to estimate cord and maternal serum ferritin in the last trimester of pregnancy and to correlate it with hematological parameters. Cord serum ferritin levels were normal in the patients under study, even when the maternal serum ferritin levels were decreased. The mean level of cord serum ferritin was $134.06 \mathrm{ng} / \mathrm{ml}$ and maternal serum ferritin was $41.65 \mathrm{ng} / \mathrm{ml}$ and was statistically significant. The hematological parameters like hemoglobin, hematocrit, MCV and MCHC were also decreased in the patients with low serum ferritin and were found to be statistically significant. Hence estimation of cord serum ferritin can be used as a biochemical marker to assess iron deficiency in the early stages itself and thereby neurodevelopmental complications in children can be prevented.

KEYWORDS: Ferritin, Hemoglobin, PCV, MCV, MCHC.

INTRODUCTION: Ferritin is a globular protein complex consisting of 24 protein subunits, and is the primary intracellular iron storage protein in both prokaryotes and eukaryotes, keeping iron in a soluble and non-toxic form. Almost, $23 \%$ of iron is bound with ferritin. Ferritin stores 500-800 mg of iron in the body .Ferritin can take 3500-4000 iron atoms/molecule ${ }^{1}$ Ferritin is a protein of $450 \mathrm{k} \mathrm{Da}$ consisting of 24 subunits that is present in every cell type. Ferritin without iron is known as "Apoferritin". It consists of an outer polypeptide shell $130 \mathrm{~A}^{0}$ in diameter with central ferrichydroxide-phosphate.

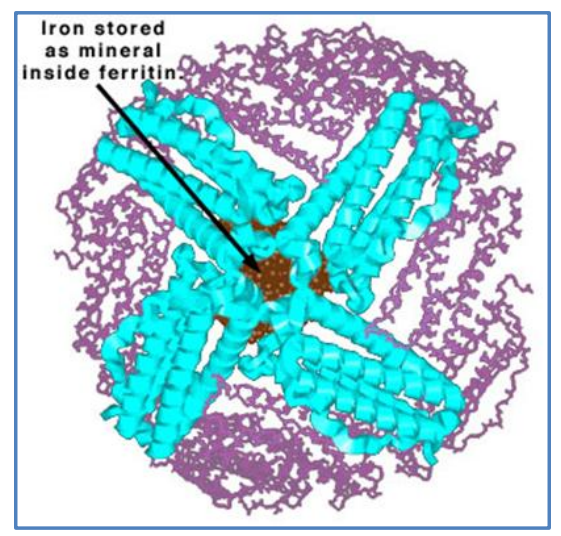




\section{ORIGINAL ARTICLE}

In the absence of iron, a repressor protein binds to the iron response element (IRE), a stemloop structure in the 5'-leader sequence of ferritin mRNA. This mRNA is sequestered for further use. Delta amino levulinic acid synthase, an enzyme of heme biosynthesis, is also regulated by a 5'IRE in its m RNA. In contrast, more ferritin receptor is needed if iron is limited; its mRNA has IREs in its 3' unsaturated region. Binding of the repressor protein stabilizes the mRNA and prolongs its lifetime. ${ }^{2}$

Low iron concentration lead to activation of an IRP (IRON REGULATORY PROTEIN) that binds mRNA for transferring receptor and ferritin. There are two types of IRP.IRP-1, is regulated by its change from active to inactive states in mRNA-binding properties. IRP-2, a second regulatory protein, also responds to varying concentrations of iron.

It is regulated by increased synthesis at low Iron concentration and increased degradation by proteosome at high iron concentration. Ferritin tends to form oligomers, and when it is present in excess in the cells of the storage organs there is a tendency for condensation to semicrystaline hemosiderin to occur in the lysosomes. This microhetrogenicity is due to difference in the contents of the acidic ' $\mathrm{H}$ ' and weakly basic ' $\mathrm{L}$ ' subunits. ${ }^{3}$

WHO has accepted up to $11 \mathrm{gm}$ percent as the normal hemoglobin level. Below $11 \mathrm{gm}$ percent in pregnancy should be considered as anemia. As iron is depleted, changes are seen first in ferritin levels and bone marrow iron, which reflect storage iron available for hematopoiesis. Serum iron and transferring saturation then fall, accompanied by a decline in mean corpuscular volume. The final manifestation of iron deficiency is Anaemia. ${ }^{4}$

The third trimester is the period where the needs for iron are the largest. Anemia in pregnancy could result in premature birth and low birth weight of fetus. Thus, it is important that the mother takes supplementary iron in her nutrition. Anemia and the fetal birth weight have a proportional relationship.

The weight of the fetus is greater if the concentration of hemoglobin is higher. A low birth weight fetus often results from preterm birth, which is another consequence of anemia. Preterm birth greatly influences the health of the fetus. Iron deficiency anemia in pregnancy can cause irreversible damage to the child's neurological function and development.

National Family Health Survey (NFHS-3) of India reveals the prevalence of anemia to be 70$80 \%$ in children, $70 \%$ in pregnant women and $14 \%$ in adults. Iron deficiency anemia has well known adverse effects on physical and cognitive performance of individuals, and also on maternal and fetal health. However, even more important, is that iron deficiency without anemia may also adversely affect long-term neurodevelopment and behavior in infants which may be irreversible. ${ }^{5}$

In contrast to the $3^{\text {rd }}$ trimester fetus in utero, erythropoiesis decreases abruptly after birth in the premature infant and the hemoglobin concentration declines at a rate of approximately 1 $\mathrm{g} / \mathrm{dl} /$ wk. during the first 1 to 13 months of postnatal life. ${ }^{6}$

Effects of iron deficiency are not limited to those of iron deficiency anemia. In addition to its key role in hemoglobin and myoglobin, iron-dependent enzymes are involved in several key metabolic pathways including DNA synthesis, mitochondrial electron transport, catecholamine metabolism, neurotransmission, and detoxification.

Iron is essential for the normal development and functional integrity of the immune system. Anorexia and failure to thrive are the complications of iron deficiency. ${ }^{7}$ Healthy newborn infants have total body iron of $250 \mathrm{mg}$, this decrease to approx. $60 \mathrm{mg}$ in the first six months of life. ${ }^{8}$ 


\section{ORIGINAL ARTICLE}

MATERIALS AND METHODS: The patients chosen for the study were 100 pregnant full term ladies and their newborn babies. And 20 non pregnant adult women in the reproductive age group as controls.

Venous blood was collected from the pregnant patients at the time of delivery along with the cord blood. Detailed baseline data of each patient including age, height, weight, previous and present history of diseases, obstetric history, family and personal history were noted. Serum ferritin of mother and cord blood were done. Mother's Hb, PCV, MCV, MCH and MCHC were done in all patients and controls. The hematological parameters were done using CELL DYN@3200.Ferritin levels were estimated by chemiluminescence using elecys 1010. Statistical analysis were done using SPSS 20.

ANALYSIS OF RESULTS: In the present study, maternal serum ferritin were below $15 \mathrm{ng} / \mathrm{ml}$ in 20 patients and normal in the remaining 80 patients. Cord serum ferritin levels were normal in all the 100 samples under study a positive correlation was seen in maternal serum ferritin and cord serum ferritin. P value is 0.00 . So it is statistically significant. It has been noticed that the mean of maternal serum ferritin is $41.6458 \mathrm{ng} / \mathrm{ml}$ and its std deviation 33.269 , whereas the mean of cord serum ferritin is $134.06 \mathrm{ng} / \mathrm{ml}$ and its std. deviation is 71.152 .

It has been noticed that whenever there is decrease in maternal serum ferritin there is no decrease in cord serum ferritin so the fetus will be safe. Hemoglobin levels decreased significantly in the present study during last trimester. $\mathrm{P}$ value is 0.00 , so it is statistically significant. Hematocrit (PCV) decreased significantly during last trimester and $\mathrm{P}$ value is significant i.e.; $\mathrm{P}$ value 0.00 when compared to controls.

MCV decreased in the samples and P value is significant, 0.00, MCHC decreased in all the samples under study when compared with controls and $\mathrm{P}$ value is significant, 0.00.A significant positive correlation was observed between ferritin and hemoglobin level. A significant correlation was also noticed between maternal serum ferritin and cord serum ferritin.

\begin{tabular}{|c|c|c|c|}
\hline & mean & p & Std. Deviation \\
\hline MATERNAL SERUM FERRITIN & 41.6458 & 0.00 & 33.26953 \\
\hline CORD SERUM FERRITIN & 134.0632 & & 71.15200 \\
\hline
\end{tabular}

COMPARISION OF MATERNAL SERUM FERRITIN AND CORD SERUM FERRITIN

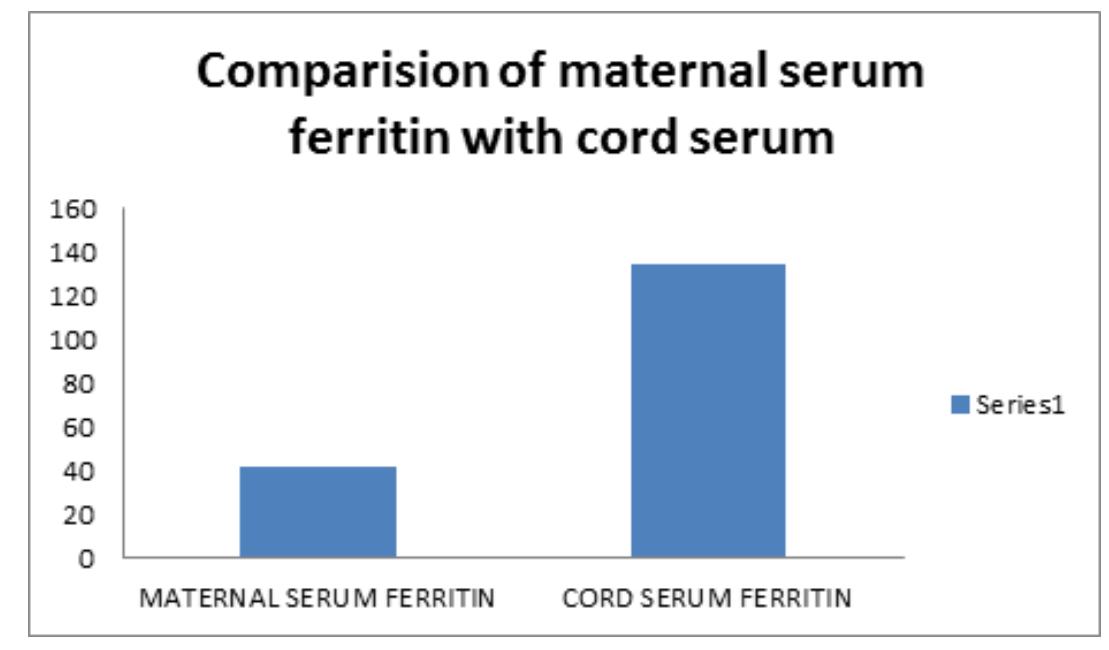




\section{ORIGINAL ARTICLE}

\section{Correlation between hemoglobin \& maternal serum ferritin 0.2999 (positive correlation):}

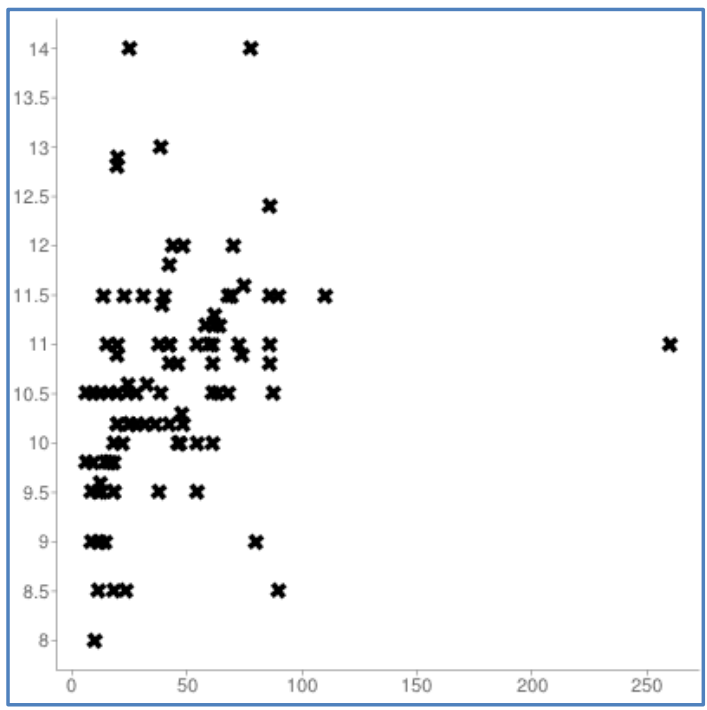

DISCUSSION: Iron Deficiency Anemia has well known adverse effects on physical and cognitive performance of individuals, and also on maternal and fetal health. However, even more important, is that Iron Deficiency without anemia also adversely affect long-term neurodevelopment and behavior in infants which may be irreversible. ${ }^{5}$

The blood levels of ferritin in the umbilical cord will not decrease until the ferritin value of the mother was $<12 \mu \mathrm{g} / 1$. Under these conditions the ferritin levels in the umbilical cord blood $(80.4$ $\mu \mathrm{g} / 1$ ) were significantly lower than in those newborn infants whose mother had adequate ferritin levels $(123 \mu \mathrm{g} / 1$.

Andrew B F, in his studies and in our studies also it is proved that babies born to iron deficient mothers are having their $\mathrm{Hb}$ con. Normal, and also their serum iron and TIBC found normal. It is also found that the placenta act as a barrier excluding excess iron and preventing fetal iron overload. Consequently, maternal iron supplementation does not influence fetal iron status.

Ferritin has a significant role in pregnancy to balance the very high iron requirements in late pregnancy. It has been noticed that whenever there is decrease in maternal serum ferritin there was no decrease in cord serum ferritin So the fetus will be safe. Estimation of cord serum ferritin level in newborns help to detect iron deficiency in the early stages and neuro developmental abnormalities in children can be prevented.

So cord serum ferittin level can be taken as a biochemical marker of iron deficiency anemia in newborns.

\section{REFERENCES:}

1. Fenton V, Cavill I \& Fischer J. Iron stores in pregnancy. British Journal of Hematology1977; 147: 9.

2. Sandhya. V, Shruthi Patil, ATK Rau. Iron store status in newborns born to anemic and nonanemic mothers. Journal of Pediatric Sciences2012; 4: 118.

3. Kelly AM, Macdonald DJ, Mc dougall AN. Observations on maternal serum ferritin. J Trop Pediatr 1991; 149: 3. 


\section{ORIGINAL ARTICLE}

4. Wick M, Pinggera W, Lehmann P. Ferritin in iron metabolism-Diagnosis of anemias, SpringerVerlag1995; ISBN3-211-82525-8 and ISBN0-387-82525-8

5. Kaltwasser JB, Werner E. Serum ferritin; Methodische and Klinsche Aspekte. Springer Verlag $1980 ; 228 ; 4$

6. Lozoff B, Jimene E, Wolf AW. Longterm developmental outcome of infants with iron deficiency. N Eng J Med 1991; 687: 94.

7. Christine Hunt, Ala I Sharara; Am fam Physician 1999; 829: 7.

8. Albertini A, Aroso P, Chaincone E, Drysdale J. Ferritins and isoferritins as biochemical markers. Elsevier Amsterdam 1984; 33: 14.

\section{AUTHORS:}

1. Sherin Stephen

2. Jyothy Kuriakose

\section{PARTICULARS OF CONTRIBUTORS:}

1. Professor and HOD, Department of Biochemistry, Academy of Medical Sciences, Pariyaram, Kannur, Kerala.

2. Lecturer, Department of Biochemistry, Academy of Medical Sciences, Pariyaram, Kannur, Kerala.

\section{NAME ADDRESS EMAIL ID OF THE} CORRESPONDING AUTHOR:

Dr. Sherin Stephen,

Professor and HOD,

Department of Biochemistry, Academy of Medical Sciences, Pariyaram, Kannur-670503, Kerala.

Email: sherin.stephen@rediffmail.com

Date of Submission: 08/07/2014.

Date of Peer Review: 09/07/2014.

Date of Acceptance: 18/07/2014.

Date of Publishing: 25/07/2014. 